\title{
Process ENGINEERING AND AI SALES PREDiCTION: THE CASE STUdy OF AN ITALian SMALl TEXTILE COMPANY
}

\author{
Nicola Magaletti ${ }^{1}$, Gabriele Cosoli ${ }^{1}$, \\ Angelo Leogrande ${ }^{1}$ and Alessandro Massaro ${ }^{1,2, *}$ \\ ${ }^{1}$ LUM Enterprise srl, S.S. 100 - Km.18, Parco il Baricentro, 70010, Bari, Italy. \\ ${ }^{2}$ LUM - Libera Università Mediterranea "Giuseppe Degennaro", \\ S.S. 100 - Km.18, Parco il Baricentro, 70010, Bari, Italy
}

\begin{abstract}
The paper describes the case study of a production process engineering applied to a company working in the textile sector and upgraded by digital technologies. The process engineering is performed by means the Business Process Modelling Notation (BPMN) approach. The new engineered processes are enabled by adopting a software platform able to extract data from work documents using a Robotic Process Automation (RPA) technology based on digital document features recognition. The implemented platform also integrates a Decision Support System (DSS) based on the estimation of priority rules and of Key Performance Indicators (KPIs) supporting subcontractor's management and related activities. Furthermore, the DSS integrates sales forecasting Artificial Intelligence (AI) algorithms. A comparative analysis about regression-based algorithms and Artificial Neural Network (ANN) Multilayer Perceptron $(M L P)$, is performed to check the best algorithm performance about the product quantity prediction in function of the price, finding ANN-MLP as a good candidate for the estimation. The ANN-MLP model is optimized to provide sales forecasting results with a low Mean Absolute Error (MAE) of 0, 00113. All the analysed algorithms are applied to an experimental dataset. The results have been developed within the framework of a Ministerial Italian project named Smart District 4.0 (SD 4.0).
\end{abstract}

\section{KEYWORDS}

Decision Support System, Process Engineering, Sales Prediction, Artificial Intelligence.

\section{INTRODUCTION}

In this section is described the general scenario of the technologies and approaches adopted in the pilot case of study. Automating repetitive tasks can produce human errors [1] that can be decreased by the adoption of the Robotic Process Automation (RPA) technology. RPA is useful to eliminate repetitive activities, to reduce the labour consumption, to assign employees to new production areas, and in general to minimize human errors [2]. Different tools can be applied for advanced data processing. Artificial Intelligence (AI) surely plays an important role in the context of business processes [3], and can be combined with RPA for data processing, especially when in the production processes are identified routinely tasks [4]-[6]. The use of AI can improve the efficiency of RPA in Industry 4.0 scenarios, by providing good application performances in data recognition, classification, and forecasting [7]. The association AI-RPA is suitable in different marketing sectors, such as finance and banking [8]-[10], thus suggesting the application also in other sectors as for the analysed case study. RPA is strictly connected to AI [11]-[12], and is suitable to construct workflows [13], to select processes [14], to digitize transactions [15], and in different cases requiring document management automation [16]-[21]. Document recognition 
by AI, can support data flow automation [22]-[23]. Automation process of practices is an industrial research topic for companies working in services and implementing association rules to improve contract classification [24]. Moreover, data warehouse and software integration such as Enterprise Resource Planning (ERP) and Customer Relationship Management (CRM), play an important role for the company Business Intelligence (BI) [24]-[26]. In this technological scenario, innovative platforms oriented on company performance integrates software tools and Key Performance Indicators (KPIs) [27]-[28], improving production activities. Production processes can be modelled and simulated by Business Process Modelling Notation (BPMN) approaches [29], suitable to map "AS IS" and "TO BE" processes [30]. The analysed state of the art, highlights that different tools can be implemented to realize an Information Technology (IT) collaborative framework, controlling and simulating company core-processes. Following the technological scenario, has been developed the Smart District 4.0 (SD 4.0) project, initiative funded with the contribution of the Italian Ministry of the Economic Development, sustaining the digitization process of the Italian Small Medium Enterprises (SMEs), by focusing the experimentation on a pilot company (GEMITEX srl), leading in the national and international market for the production and marketing of tablecloths, cushions, chair covers, ironing board covers, carpets, bathroom and kitchen furniture, doormats, sheets, quilts, curtains and other items for home. The pilot company manages different subcontractors. For this purpose, the main process to optimize is the subcontractor's management by means of Decision Support System (DSS) based on priority rules and KPIs. This is possible by digitizing information by RPA. A further important requirement of the pilot industry, is to have graphical dashboards based on AI predicting sales. Following the company's need, the IT platform is designed for the case of study to trace production and marketing activities, and to optimize subcontractor's management. The paper follows the development of the project stages describing:

- "AS IS" scenario of the pilot company managing subcontractors;

- design of the "TO BE" business model obtained adding SD 4.0 digital facilities;

- design of the experimental platform describing, by means of a Unified Modeling Language (UML) Use Case Diagram (UCD), all the data fluxes involving the actors of the whole systems;

- interfaces of the platform about some important functions including RPA, and subcontractors' monitoring dashboards;

- experimental results about Konstanz Information Miner (KNIME) sales prediction by comparing results of different AI algorithms.

\section{2. “AS IS" AND “TO BE" ProCESSES AND UML PlATFORM DESIGN}

In the preliminary analysis of the "AS IS" process, emerges that the pilot company (GEMITEX srl) carried out production starting with the receiving of orders of items having particular technical-functional and aesthetic characteristics, which can be selected from a catalogue or according to customer specifications. Upon receipt of the customer order, the latter was inserted into the Enterprise Resource Planning (ERP) system, making available the total production data, and sub data sheets to be distributed to the various subcontractors. For $99 \%$ of cases, each process necessary for the realization of a product in the catalogue corresponds to a single specialized subcontractor. For each subcontractor a long-term loyalty relationship is established. In the event that a process can be carried out by several actors, the subcontractor is selected by evaluating his workload. The workload of subcontractors was acquired through telephone communication. The logistics for the delivery of materials to subcontractors, was carried out by an employee who coordinates the suppliers by telephone (date and time of ready products, volumes, etc.), providing usually a time delay because the telephone call does not always guarantee an answer. In Fig.1 (a) is illustrated the "AS IS " architecture of the operating model 
for subcontractor's management. The SD 4.0 platform, sketched in Fig. 1 (b), through a userfriendly user interface is able to manage each individual order, by analysing the data flow of the whole supply chain, and by managing the activities of order initiation, plans, executions, and order processing in each phase. The new platform allows the pilot company to monitor, through a control checklist, the percentage of progress of the work performed and to conduct detailed analysis on each task in progress. Moreover, the platform provides a statistical analysis of the performed work (load on subcontractors, causal on the problems, etc.) through graphical dashboards tracking the order in each step.
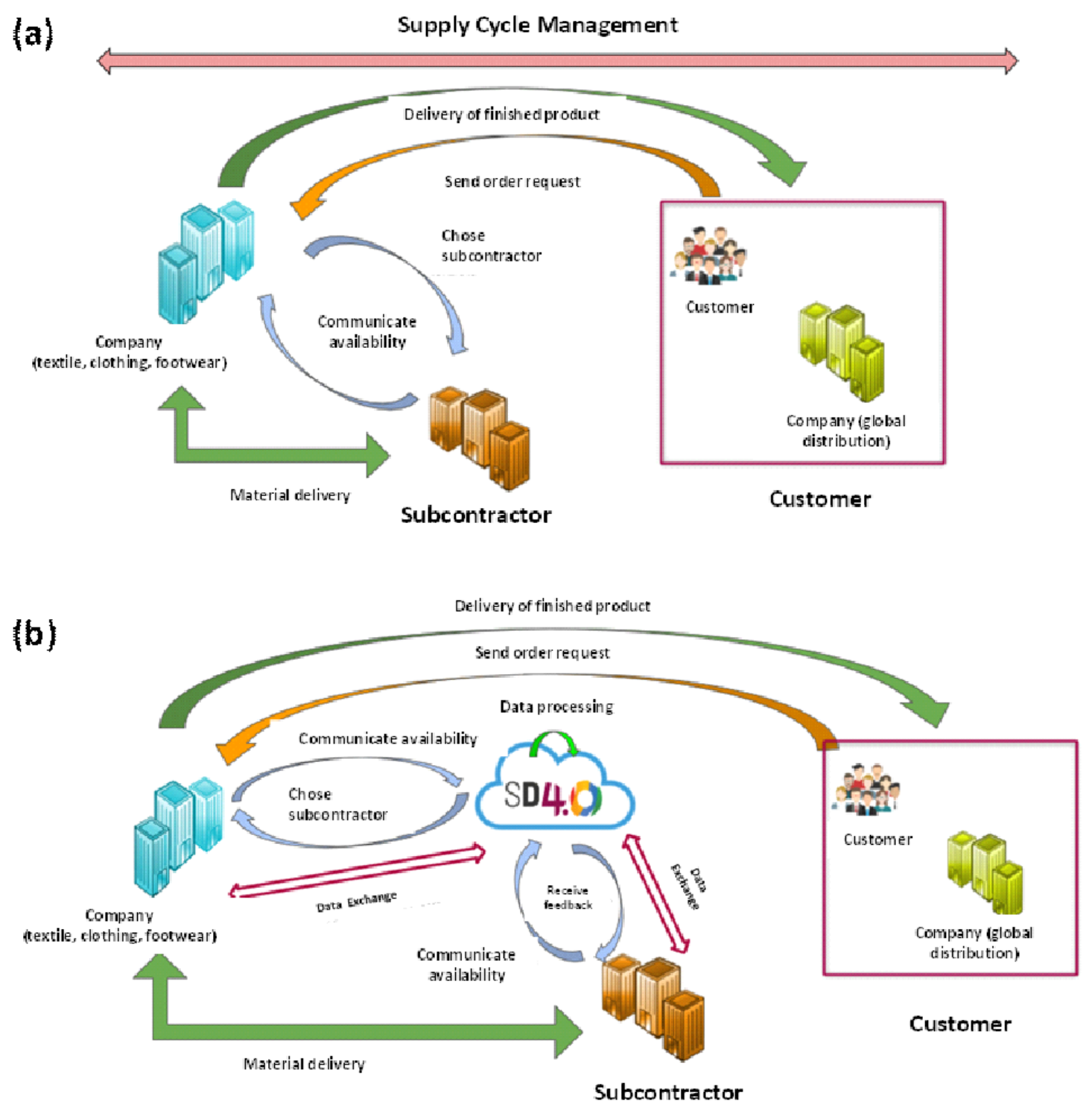

Figure 1. (a) "AS IS" and (b) "TO BE" main architectures.

As shown in the BPMN "AS IS" processes of Fig. 2 and Fig. 3, most of the activities in the GEMITEX srl pool was carried out by internal staff, with a very low automation level. It is then possible to intervene on the first activities of the process, carried out after receiving the order from the customer, by automating the process of data insertion in the ERP system matching with the order template. The first improvement goal of the "TO BE" process is then to reduce the 
workload of operators, and to allow the automatic processing of production sub-sheets starting from the total production sheet. After the creation of the production sub-sheets (sub-datasheet), the individual sub-orders must be assigned to the specific subcontractors, specialized in the processing necessary for the creation of the items concerning the order. For the monitoring of subcontractor assigning process, it is necessary, before to check the availability of the subcontractor, to carry out the processing within the required time. The verification of the subcontractor's workload was previously carried out by telephone by the GEMITEX srl operators. For this purpose, a goal of the "TO BE" process is to show the subcontractors availability immediately by automating the checking process. In the new process, the subcontractors can be enabled to interact with the SD 4.0 platform, through dedicated users in order to be able to enter digitally their work commitments on a digital calendar. In this way, the SD 4.0 platform can record the availability of all subcontractors, thus guaranteeing a simplified management of the same and with a low number of interactions. Although, in the previous process, the same types of processing were assigned most of the time to the same subcontractors, and a human operator was always employed in the assignment of subcontracts to subcontractors. A further improvement goal of the "TO BE" scenario, is then to automate the assignment of suborders by exploiting self-learning techniques on the historical data of the assignments, leaving the human operator only to validate the proposed assignments. In the previous process, there was a not well-structured order priority management of subcontractors. This management was based mainly on the experience of the GEMITEX srl operators managing the priority order variations by phone. In this direction, the process improvement is in the automatic management of the notification of the order priorities to manage subcontractors the related suborders. The "AS IS" process of Fig. 2 explains in detail the activities performed by the company for the management of the orders and suborders: the process started from the GEMITEX srl pool which acquires from the ERP the information of the order to know the processing status. If the processing is not yet started, the company prepares the material and sends it to the subcontractor for the processing, otherwise contacts the subcontractor by telephone to get an update on the percentage of progress. Depending on the workload, and therefore the availability of the moment, the subcontractor could reject the call or answer the phone. In the first case, the company does not receive any information and is forced to call back at a later time. In the second case the subcontractor analyses the request of the pilot company, retrieves the data relating to the asked order and, finally, communicates the percentage of progress of the work. The company analyses the processing status and, if the deadline is not respected, discusses by telephone with the subcontractor to identify together problems for an agreement about a recovery action. When the subcontractor completed the processing phase and the sub-order, himself prepares the materials for delivery, and contacts the company by telephone to communicate product availability and the related characteristics (volume, weight, etc.). The "AS IS" process ends with the organization of the external logistics by checking the availability of transport vehicles, and by communicating to the subcontractor information (date and time). 


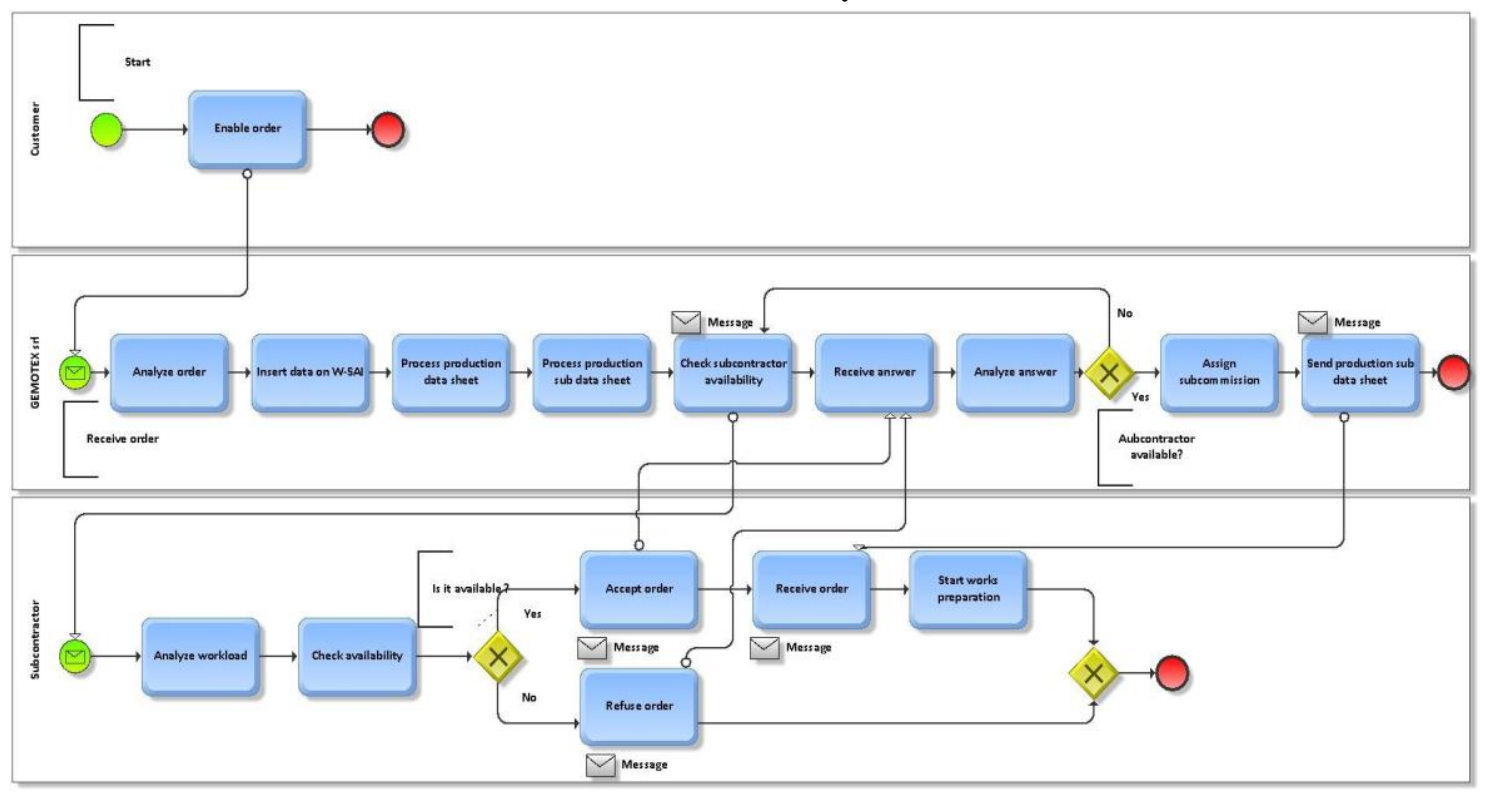

Figure 2. BPMN model: “AS IS" order and sub-order management process.

In the "AS IS" process of Fig. 3, it is observed how the management of the orders and of the suborders is a manual process carried out by an operator: it is evident that there is a no real-time monitoring of orders, that any delays in processing are almost always discovered after their occurrence, making recovery actions difficult. So, it is important to reduce manual activities of operators by allowing the real-time monitoring of the progress of orders and suborders through the SD 4.0 platform, building a synoptic dashboard, tracking activities and sending automatic alerts via the platform if the set deadlines are not respected. In the "AS IS" process there is not any activity to evaluate the performance of the subcontractor who worked on a suborder: the merit assessments of the various subcontractors are not formalized and historicized, remaining only in the memory of the operators who followed the process and carried out the checks. The introduction of subcontractor's KPIs, therefore becomes useful for their efficient assignment. Finally, in the "AS IS" process there is not an assistance service provided to subcontractors when problems arise during the processing phases: any problem could cause a production block to be resolved through only a telephone call. In this direction, a chatbot virtual assistance is able to allow the subcontractor to quickly receive possible solutions and resume work in a short period of time.

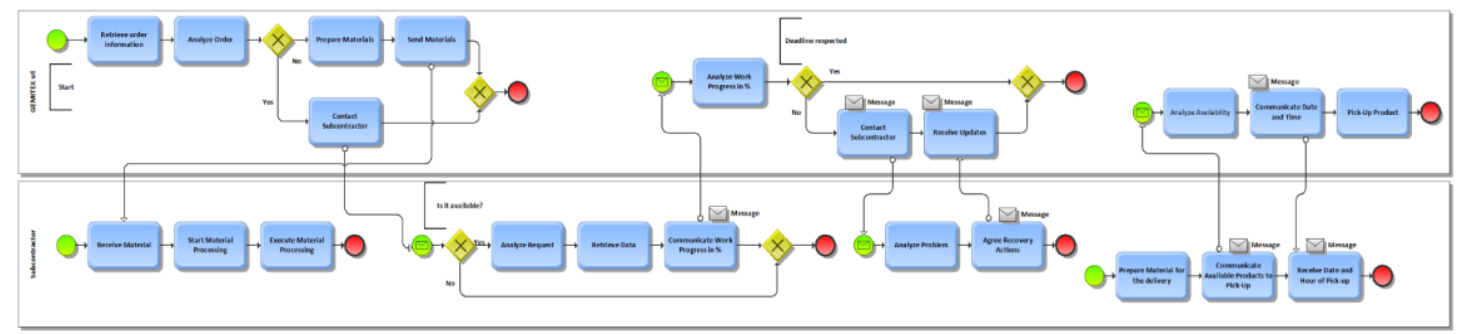

Figure 3. BPMN model: "AS IS" process of orders and sub-orders management process.

The engineering of the production process ("TO BE" process), starts with the digitization process of the production sheet which represents the first important stage to digitally control the company processes. When GEMITEX srl receives an order request, the platform generates a "total production sheet" through the ERP, containing all the information such as, customer, delivery 
date, quantity, etc. By solving the criticalities of the "AS IS" analysis, the SD 4.0 project platform includes different functions such as:

- automatic processing of production sub-sheets;

- the check on the technical skills and availability of the subcontractors to carry out one or more processes;

- automatic evaluation of KPIs;

- choice of subcontractors to whom to entrust sub-orders;

- storage of subcontractor / product associations;

- automatic sending of order request notifications.

The "TO BE" process begins when the pilot company uploads the total production sheet in pdf format into the SD 4.0 platform data warehouse, by means of an RPA tool, able to analyse its content, and creating automatically the production sub-sheets, containing a set of products that subcontractors must create or make available. The technical specifications for the processing of the individual products and the deadline are information contained in the production sheet, which are reported in the production sub-sheets together with the order priority and the estimated processing time. Once the automatic creation of the sub-sheets has been completed, the platform transmits them to the pilot company which assigns the priority and the estimated processing time to complete the sub-order; in this way the subcontractor who receives more orders is able to independently manage the priorities considering the company needs. The subcontractor list is filtered based on the of the subcontractor to produce the required items (the availability is identified by considering the time required for the order processing and the deadline). The platform sorts the list of subcontractors in order of performance by evaluating the average of the KPIs of each one. Finally, the platform assigns the suborder to the first subcontractor of the updated list, stores the subcontractor/product associations validated by the pilot industry, and automatically sends the notification of the order request to the subcontractor. In Fig. 4 is illustrated the graphic representation of the new process managing orders and suborders. The order management process allows the company to monitor the progress of each suborders and to organize logistics. The indicators estimated by the platform are:

- job order and suborders progress monitoring (\% of progress);

- alert on sub-order delays;

- logistics management for the delivery of raw materials;

- logistics management for the collection of semi-finished products.

GEMITEX srl, through the SD 4.0 platform, selects the order of interest from the list of all active orders, or enters the Identification Number (ID) of the same directly in the search field. The platform receives the input, analyses the order number, retrieves the corresponding information, and returns the data of the associated production sub-sheets and of related subcontractors. At this point, the company selects the sub-sheet of interest and follows the progress of the work. If the processing is not yet started, the company prepares the material and sends it to the subcontractor, who executes the work by recording the processing progress percentage on the SD 4.0 platform. This process guarantees GEMITEX srl, the real-time monitoring of the progress of the suborder which is always updated. At the end of the process, the subcontractor prepares the material for delivery. When the percentage of progress of the suborder corresponds to $100 \%$, the platform sends a notification informing the process completion. If the processing is not finished, the platform performs a check by considering the processing status and the deadline. If the subcontractor does not complete the processing the day before the order deadline, an alert notification is sent. 
International Journal of Data Mining \& Knowledge Management Process (IJDKP) Vol.12, No.1, January 2022

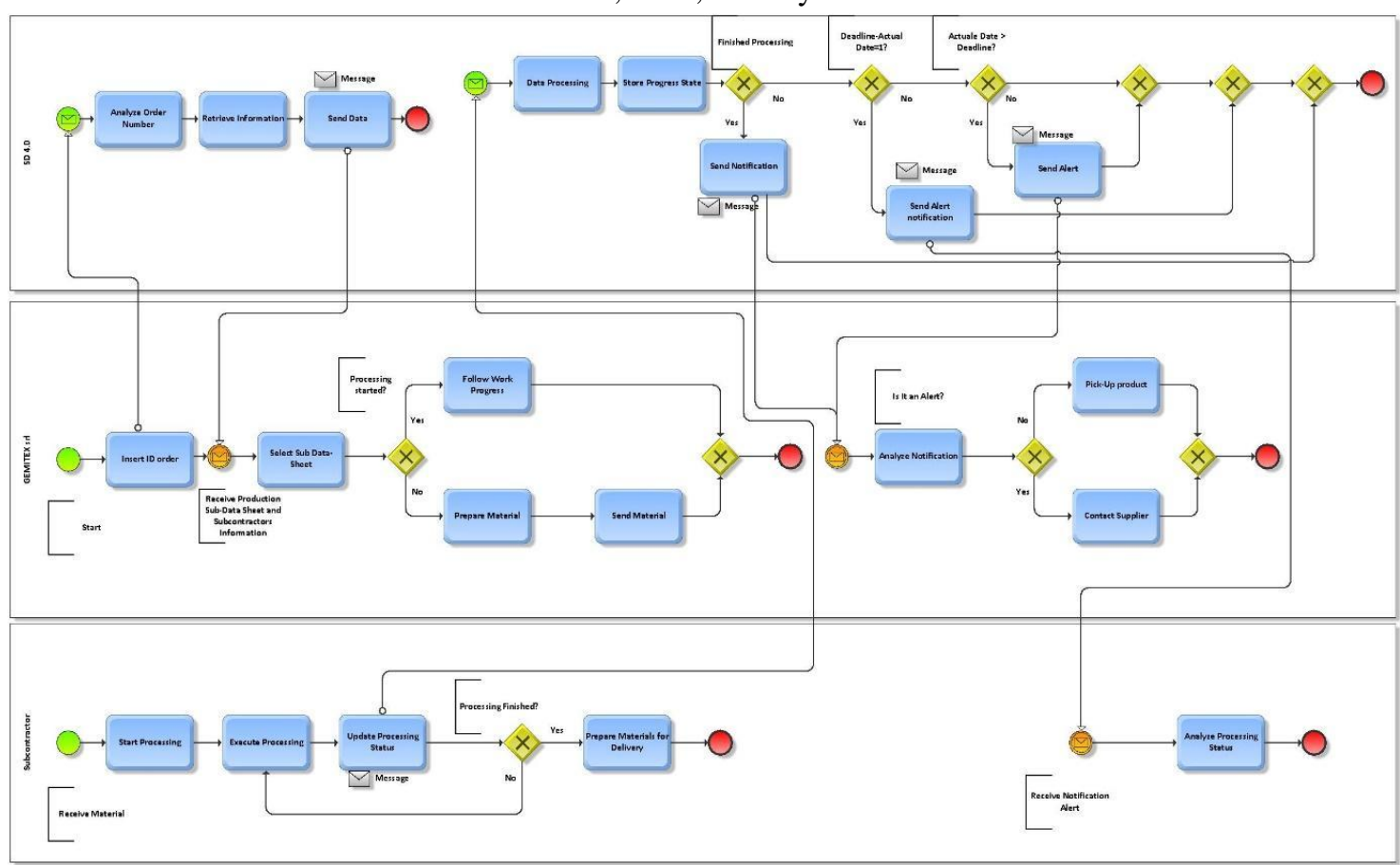

Figure 4. BPMN model: "TO BE" process of orders and suborders management.

Through the SD 4.0 platform, the process allows also the storage of opinions (feedback) expressed by the pilot company regarding subcontractors: (i) the company, having received the final product, enters the order ID in the SD 4.0 platform for the purpose of compiling and sending feedback; (ii) a screen of the sub-orders belonging to the order ID and the related subcontractors is automatically generated; (iii) the KPIs output are added in the platform (time, number of delivers in advance or in time with respect to the deadline, total number of deliveries, total number of compliant products, total number of products). The BPMN process describing subcontractors feedback system is illustrated in Fig. 5.

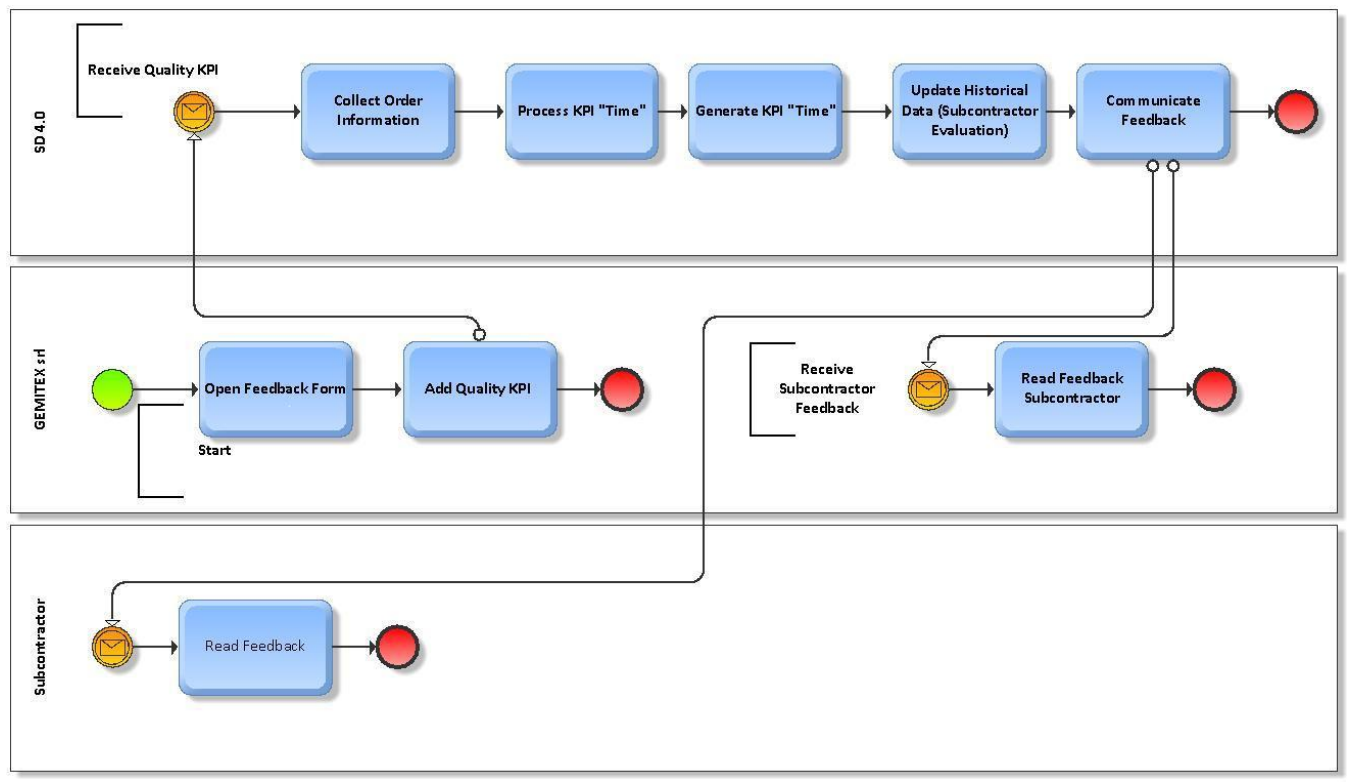

Figure 5. BPMN model: "TO BE” process subcontractors feedback system. 
In Fig. 6 is illustrated the UML UCD diagram representing the whole dataflow of the SD 4.0 platform, matching with the "TO BE" process, and involving all system actors such as subcontractors, customers and the pilot company.

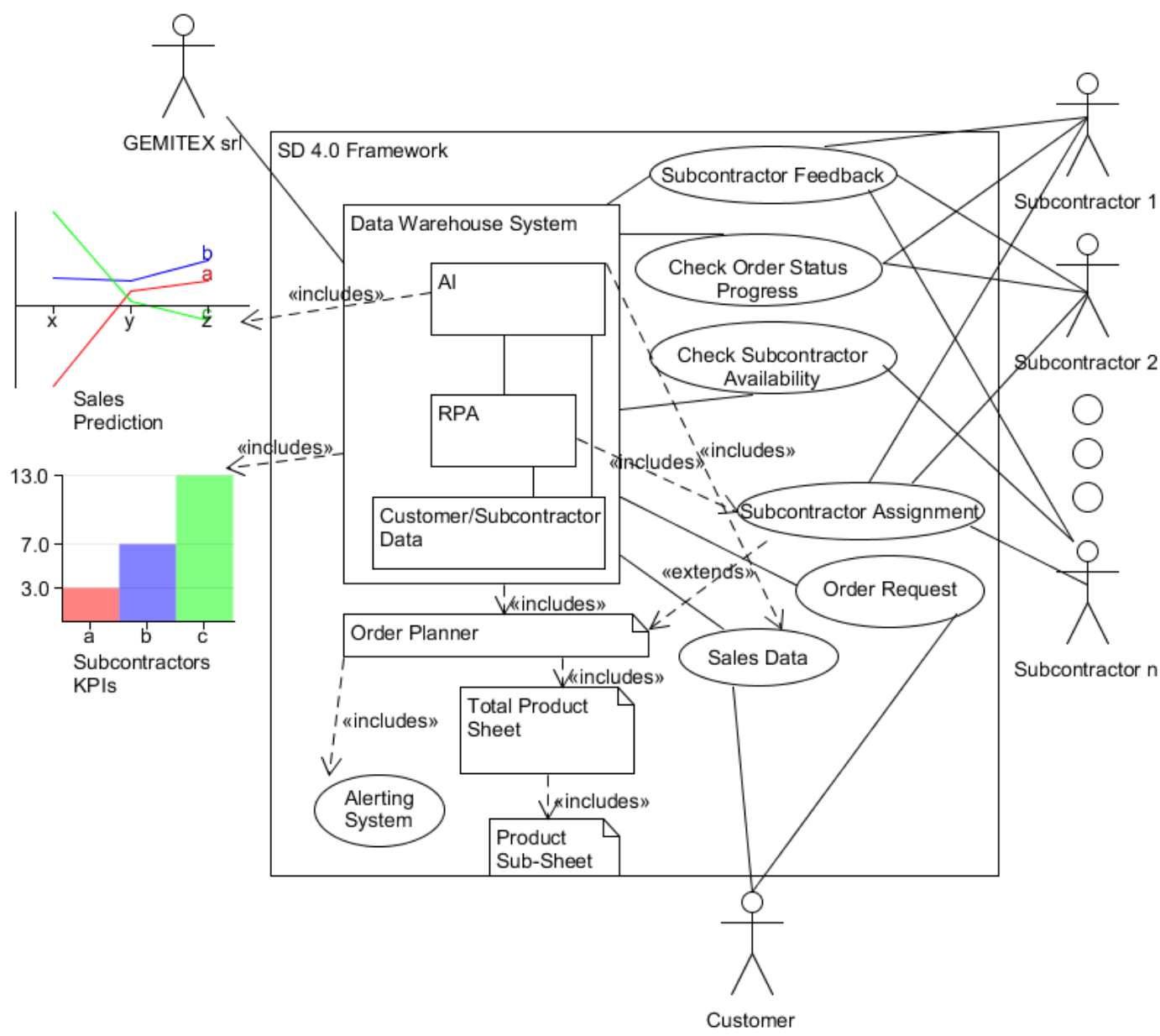

Figure 6. UML UCD diagram describing actors' dataflow of the SD 4.0 platform and related functions.

\section{SD 4.0 PLATFORM IMPLEMENTATION OF INTERFACES FOR SUbCONTRACTORS MANAGING}

A main goal of the platform, is to create the production sub-sheets starting from the total product sheet by considering the following requirements:

- the sub-sheets are easily identifiable by image features recognition, because a white line is inserted between one and the other in the total product sheet (which precisely marks the transition from one sub-tab to the other);

- the order is divided into suborders based on the involved subcontractors;

- to each subcontractor can be associated with more products.

In Fig. 7 is illustrated a typical document layout to scan and to digitize for the automatic creation of production sub-sheets. The RPA in this case is able to recognize the layout features, thus generating the interface output of Fig. 8, where the user is able to add subcontractors' priorities. 
The DSS engine of the platform is able to identify the white raw scans consecutively the patterns (table layouts), by distinguishing subcontractors' assignments and assigning processing priorities. In Fig. 9 (a) and Fig. 9 (b) illustrating the SD 4.0 dashboards outputs about order processing status and scheduling. The feedback scoring of subcontractors can be visualized by the dashboard of Fig. 10. The scoring represents a very important KPIs, and it is also important for decision making to assign priorities in the future assignments.

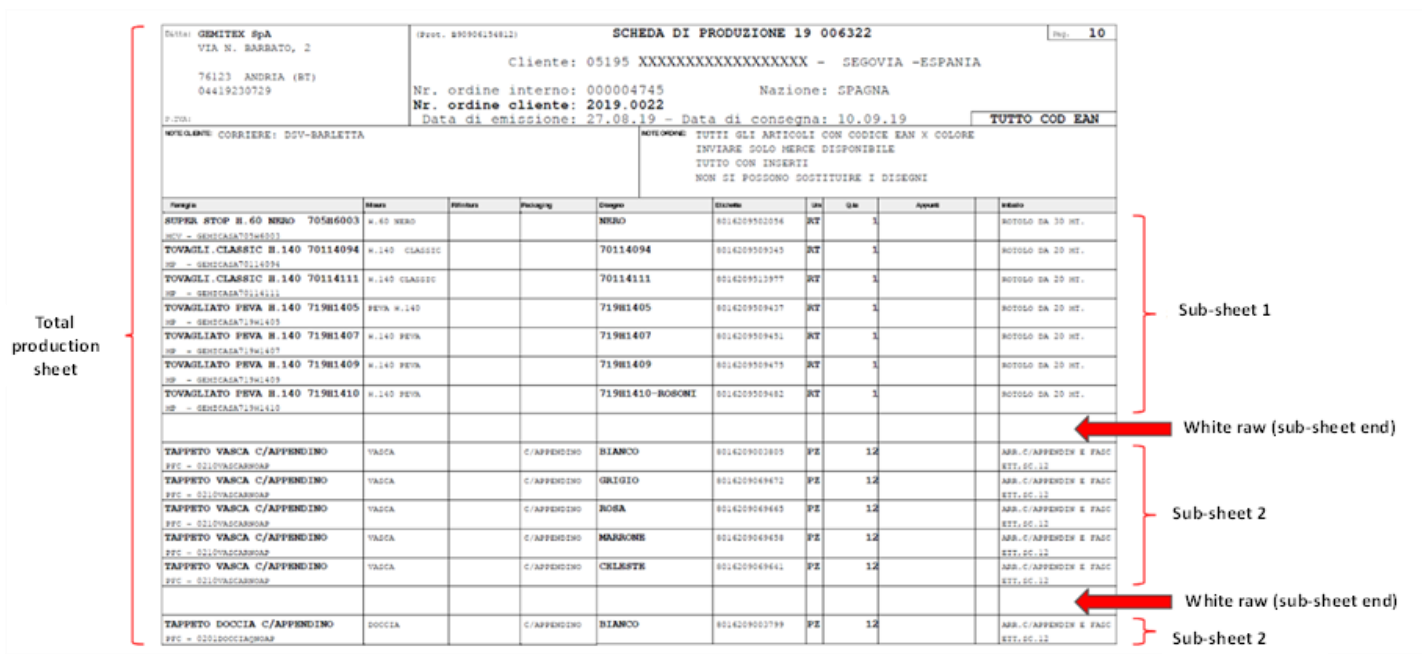

Figure 7. Total product sheet and automatic procedure to create a sub-sheet.

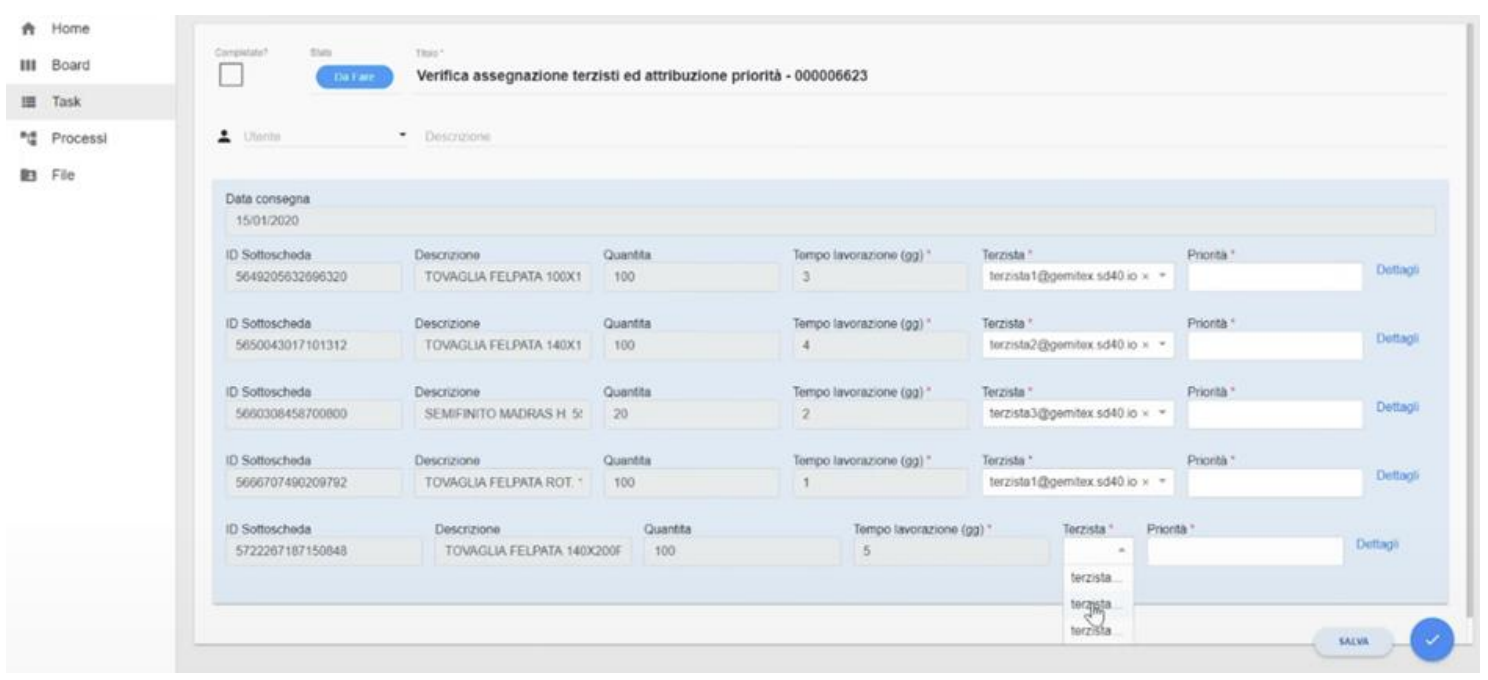

Figure 8. Interface output of the SD 4.0 platform providing subcontractor sub-sheets with priority field ("Priorità"). 
International Journal of Data Mining \& Knowledge Management Process (IJDKP)

Vol.12, No.1, January 2022

(a)

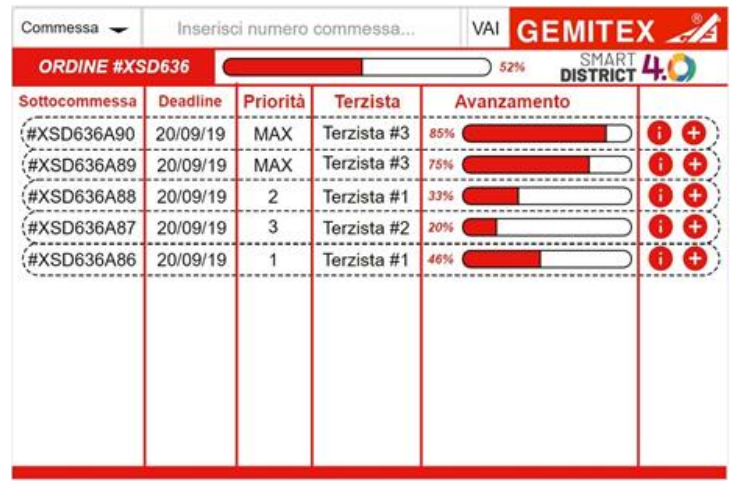

(b)

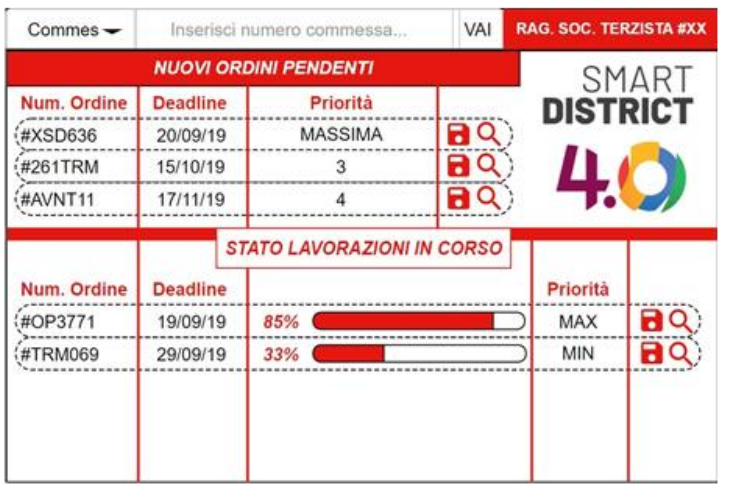

Figure 9. (a) Graphical dashboard indicating subcontractors ("Terzista") processing status. (b) Order scheduling indicating processing status and priorities.

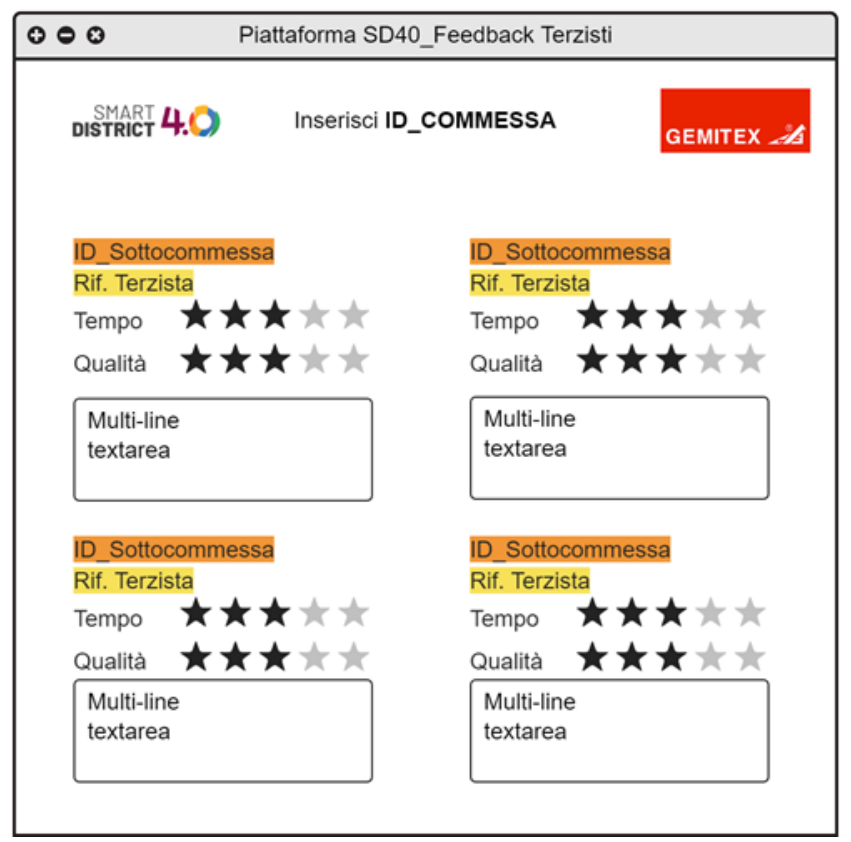

Figure 10. Dashboard for subcontractor feedback provided by Gemitex srl (subcontractor KPI).

\section{Experimental Dataset and Machine Learning Application: SALes Prediction Dashboards}

A further function of the realized platform is the availability of sales prediction graphical dashboards. Experimentation about sales prediction is performed by processing GEMITEX srl dataset collected into the SD 4.0 data warehouse. The dataset is composed by following main attributes:

Fatturato_doc_rif_documento: document code;

Fatturato_doc_data: sales date;

Fatturato_doc_cod_nazione: code identifying sales in national territory;

Fatturato_doc_des_nazione: code identifying possible nations;

Fatturato_doc_des_zona: code identifying sales in each region; 
International Journal of Data Mining \& Knowledge Management Process (IJDKP)

Vol.12, No.1, January 2022 recorded;

geo_provincia_cliente: indicates the province of the region in which the sales are

- Fatturato_doc_cdart: this attribute highlights the number of invoices associated with particular types of products;

Fatturato_doc_dsart: this attribute indicates the number of invoices that are associated with particular types of products;

- Fatturato_doc_prezzo_lordo: gross unit price;

- Fatturato_doc_perc_sconto_medio: recurring discounts within the represented dataset;

- Fatturato_doc_prezzo_netto: net price of the products that have been sold;

- Fatturato_doc_valore_venduto: represents the amount of total sales following the application of the discounts.

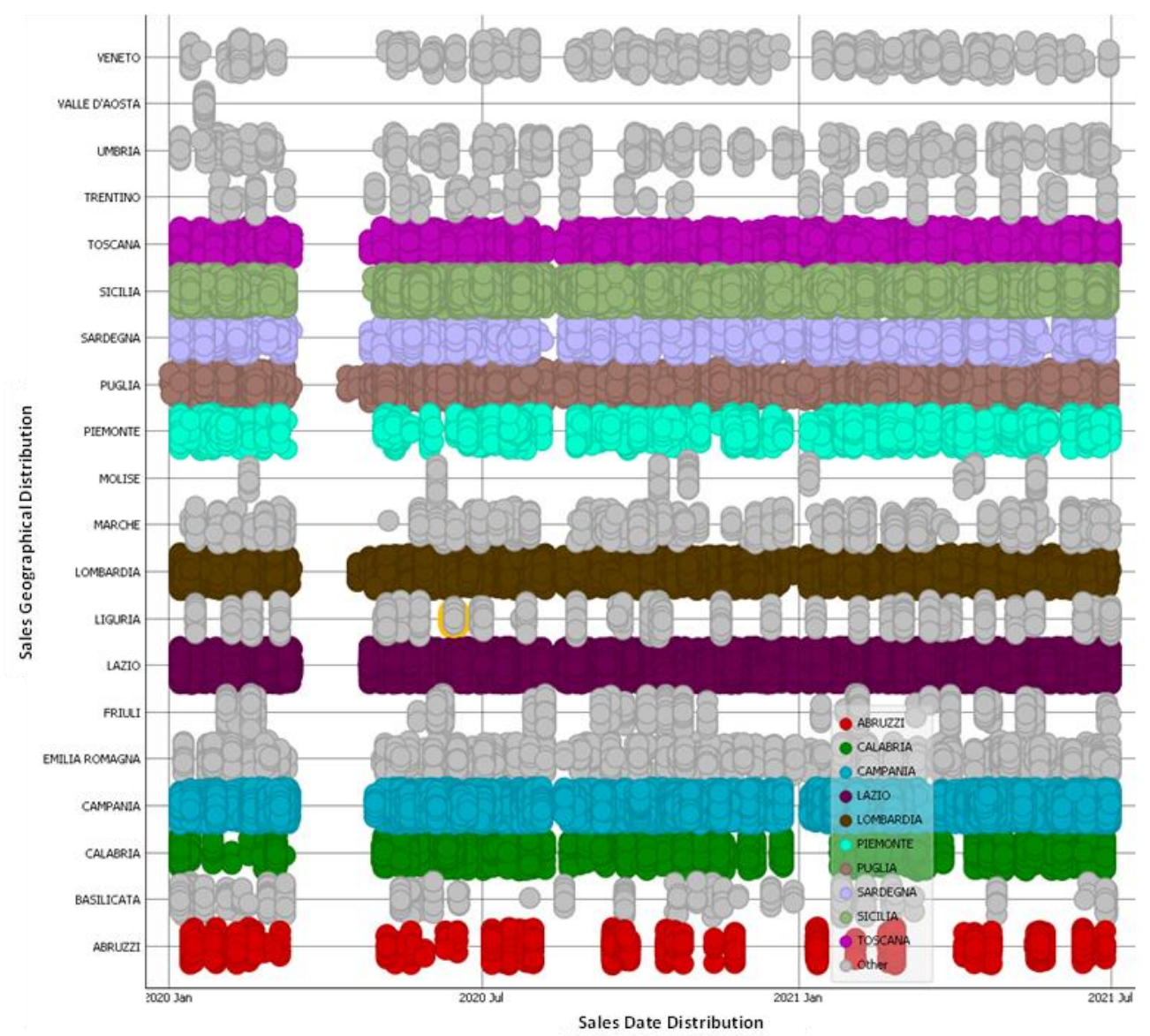

Figure 11. Plotting of the experimental dataset.

Different objects oriented open source tools [31]-[34], can be adopted for the prediction of the total product quantity (key-attribute defined as labelled class in the AI supervised algorithm), thus predicting sales of the pilot company. The tool adopted for calculus is KNIME [33]-[36], able to test the dataset model, by Artificial Neural Network (ANN) Multilayer Perceptron (MLP), the Simple Regression Tree (SRT), and the Linear Regression (LR) [37] approaches. In Table 1 are indicated the Mean Absolute Error (MAE) values for each tested algorithm, where ANNMLP exhibits the best performance, adopting KNIME standard hyperparameters and setting. 
International Journal of Data Mining \& Knowledge Management Process (IJDKP)

Vol.12, No.1, January 2022

Table 1. MAE comparison between different data mining algorithms.

\begin{tabular}{|l|c|c|c|}
\hline \multicolumn{4}{|c|}{ MAE Ranking of algorithms } \\
\hline Rank & Algorithms & Standard Hyperparameters and algorithm setting & MAE \\
\hline 1 & ANN-MLP & $\begin{array}{c}\text { Maximum number of iterations = 100; number of } \\
\text { hidden layers = 1; number of hidden neurons per } \\
\text { layer = 10; first dataset partition = 70\% (training } \\
\text { dataset); second dataset partition = 30\% (testing } \\
\text { dataset). }\end{array}$ & 0,00123 \\
\hline 2 & SRT & $\begin{array}{c}\text { Use binary splits for nominal attributes; missing } \\
\text { values handling (XGBoost) }\end{array}$ & 0,06766 \\
\hline 3 & LR & $\begin{array}{c}\text { Missing values are not considered in the calculus } \\
\text { ('fain on observing missing values') }\end{array}$ & 0,16441 \\
\hline
\end{tabular}

In Fig. 12 (a),(b), (c) are illustrated the KNIME workflow executed for ANN-MLP, SRT algorithms, respectively.

(a)

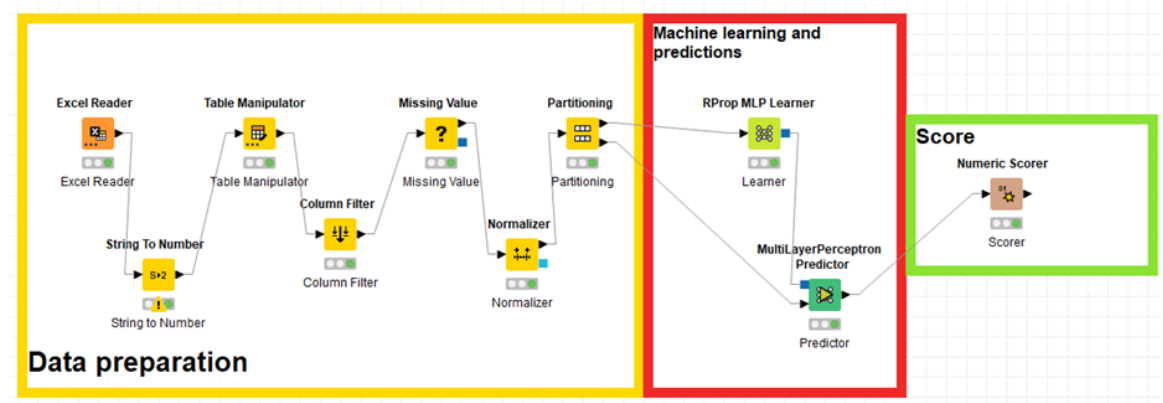

(b)

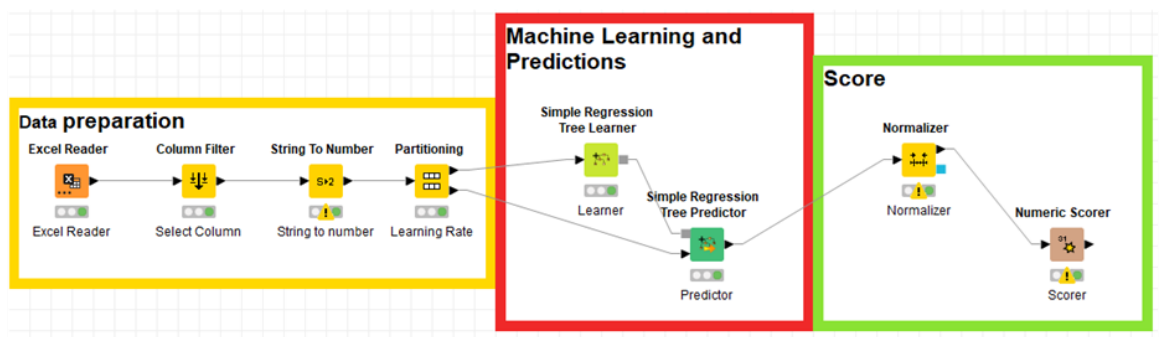

(c)



Figure 12. KNIME workflows: (a) ANN-MLP; (b) Simple Regression Tree Learner; (c) Linear Regression. 
At this point it is improved the optimization of the ANN-MLP model by following the MAE minimization approach discussed in [31], finding the best hyperparameters performing a MAE of 0,00113 (maximum number of iterations $=700$; number of hidden layers $=3$; number of hidden neurons per layer $=12$ ). In Fig. 13 (a), (b) and (c) are indicated the steps followed during the calculus to find minima conditions. The optimized ANN-MLP model is adopted to estimate the level quantity as a function of price. Specifically, in Fig. 13 (d) is predicted the product quantities $\mathrm{Q}$ as a function $\mathrm{f}$ of the invoice $\mathrm{P}(\mathrm{Q}=\mathrm{f}(\mathrm{P}))$. The prediction shows that there are two different characteristics of the predicted data:

- there is a main intensive interval in which quantities are between the denormalized value of 7.827 and 7.920 ;

- there is a growth in the maximum value of quantities that can be sold positively associated with the increase of values with the records chronologically sorted (estimation in a period of about 5.4 months).

Specifically, in Fig. 13 (d), it is clearly identified the quantities that are more recurrent under the yellow line.
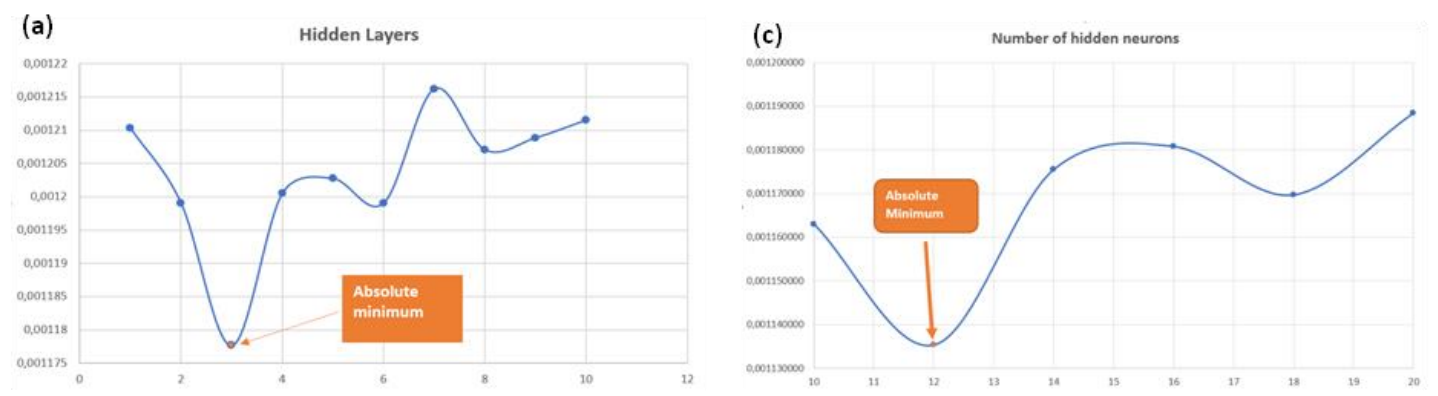

(b)

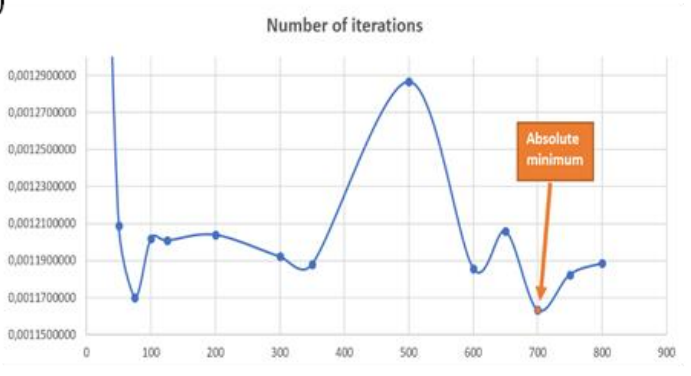

(e)

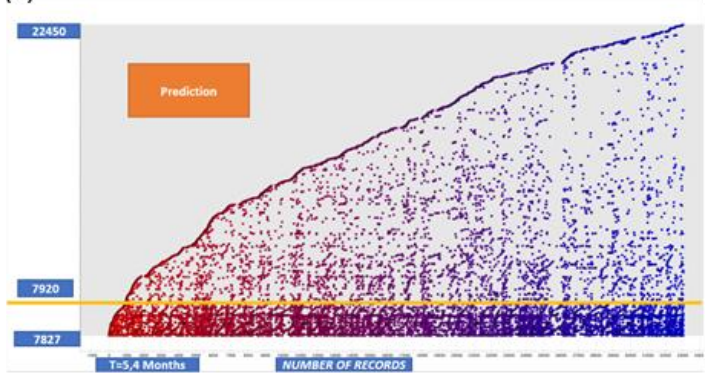

Figure 13. (a), (b), (c) MAE minimization approach [34],[36] (training dataset partition = $70 \%$; testing dataset partition $=30 \%$ ): (a) MAE versus hidden layers number; (b) MAE versus iterations number; (c) MAE versus numbers of hidden neurons per layer. (d) Prediction of quantities versus the number of the records chronologically sorted:

The prediction of quantity as a function of price: the $\mathrm{x}$-axis is representative of the number of records; the $y$-axis is representative of the quantity; specifically, it is found that there is a main interval in which the main part of records resides that is included in the interval 7.827-7.920 under the yellow line in the graph; the same graph also shows the presence of another characteristic of the dataset, i.e. the tendential growth of the maximum amount of quantity per number of records.

In Fig. 14 is illustrated the ANN-MLP architecture of the optimized predicting model. 


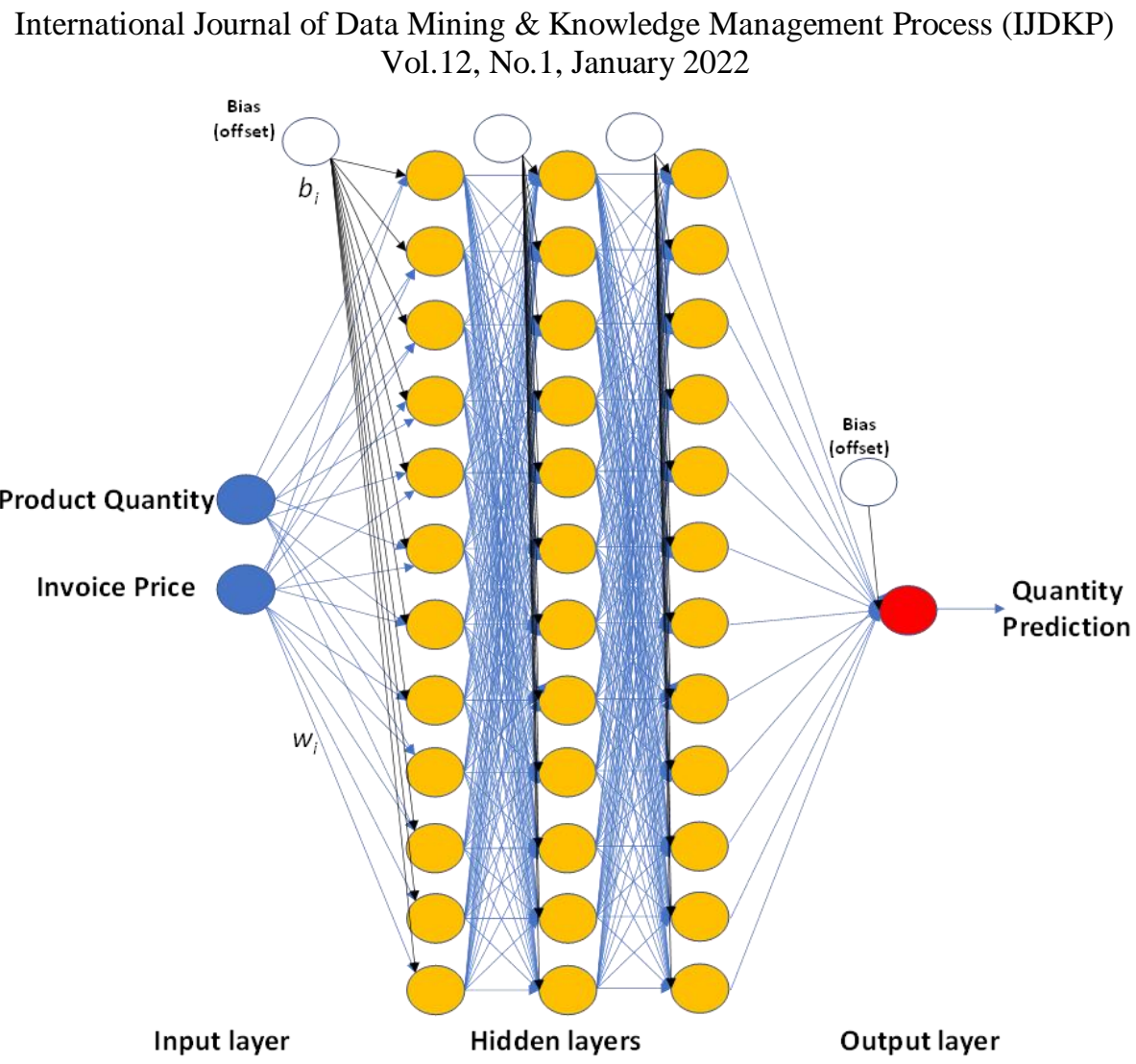

Figure 14. Optimized ANN MLP network adopted for quantity prediction.

\section{Conclusions}

The proposed paper describes an innovative platform implementing engineered processes of a company working in the textile sector. Specifically, the SD 4.0 is able to efficiently manage subcontractors and orders, by means of intelligent digital document processing tools and graphical KPIs, by indicating processes progress status with alerting system, and subcontractors' performances. The management of subcontractors is optimized by an engineered process enabling automatization and a dynamic scheduler tracing the order status and subcontractor activities. The platform behaves as a DSS, providing also important advanced analysis such as sales prediction. Different algorithms such as ANN-MLP, SRT and LR, have been tested by comparing performances. The results select as best predictor the ANN-MLP approach, able to minimize the MAE. Finally, using an optimized ANN-MLP model, it is predicted the product quantity sold in a period, by providing further graphical dashboards useful for managers. The platform is properly developed for the case study, and the related database is linked to open source KNIME workflow for data analysis. The pilot study is useful to understand the approaches and the methods to follow to improve intelligence into software tools oriented on the optimization of management of activities of the whole supply chain.

\section{ACKNOWLEDGEMENTS}

All the applications have been deployed by a unique IT collaborative framework developed within the Smart District 4.0 Project: the italian Fondo per la Crescita Sostenibile, Bando "Agenda Digitale", D.M. Oct. 15th, 2014, funded by "Ministero dello Sviluppo Economico". This is an initiative funded with the contribution of the Italian Ministry of Economic Development aiming to sustain the digitization process of the Italian SMEs. Authors thank to the 
International Journal of Data Mining \& Knowledge Management Process (IJDKP)

Vol.12, No.1, January 2022

partner Noovle for the collaboration provided during the work development. The proposed results are used to verify the usability of the data on the platform.

\section{REFERENCES}

[1] C. C. Osman (2019) "Robotic process automation: lessons learned from case studies," Informatica Economica, vol. 23, no. 4, pp. 66-75, 2019.

[2] J. Banas, "Robotic process automation. trends, expectations and adaptation opportunities in the organization," Expanding Horizons: Business, Management and Technology for Better Society, ToKnowPress, 2020, pp. 441-441.

[3] T. Chakraborti, V. Isahagian, R. Khalaf, Y. Khazaeni, V. Muthusamy, Y. Rizk and M. Unuvar, "From Robotic Process Automation to Intelligent Process Automation," International Conference on Business Process Management, 2020, pp. 215-228.

[4] V. Leno, A. Augusto, M. Dumas, M. La Rosa, F. M. Maggi and A. Polyvyanyy, "Identifying candidate routines for robotic process automation from unsegmented UI logs," 2nd International Conference on Process Mining (ICPM), 2020, pp. 153-160.

[5] J. Gao, S. J. van Zelst, X. Lu and W. M. van der Aalst, "Automated robotic process automation: A self-learning approach," OTM Confederated International Conferences On the Move to Meaningful Internet Systems, pp. 1-18, 2019, DOI:10.1007/978-3-030-33246-4_6.

[6] B. Agaton and G. Swedberg, "Evaluating and developing methods to assess business process suitability for robotic process automation," Master's Thesis in Software Engineering, Department of $\begin{array}{llll}\text { Computer } \quad \text { Science } & \text { and }\end{array}$ https://publications.lib.chalmers.se/records/fulltext/255664/255664.pdf .

[7] J. Ribeiro, R. Lima, T. Eckhardt and S. Paiva, "Robotic Process Automation and Artificial Intelligence in Industry 4.0-A Literature review," Procedia Computer Science, vol. 181, 2021, pp. 51-58.

[8] İ. Met, D. Kabukçu, G. Uzunoğulları, Ü. Soyalp and T. Dakdevir, "Transformation of Business Model in Finance Sector with Artificial Intelligence and Robotic Process Automation," Digital Business Strategies in Blockchain Ecosystems, 2020, pp. 3-29.

[9] A. Maček, M. Murg and Ž. V. Čič, "How robotic process automation is revolutionizing the banking sector," Dirsehan, T. (Ed.) Managing Customer Experiences in an Omnichannel World: Melody of Online and Offline Environments in the Customer Journey, Emerald Publishing Limited, Bingley, 2020, pp. 271-286. https://doi.org/10.1108/978-1-80043-388-520201020.

[10] A. Stolpe, H. Steinsund, J. Iden and B. Bygstad, "Lightweight IT and the IT function: experiences from robotic process automation in a Norwegian bank," Norsk konferanse for organisasjoners bruk at IT, vol. 25, no. 1, 2017.

[11] M. Romao, J. Costa and C. J. Costa, "Robotic process automation: A case study in the banking industry," IEEE 14th Iberian Conference on Information Systems and Technologies (CISTI), 2019, pp. 1-6.

[12] C. T. Kaya, M. Türkyllmaz and B. Birol, "Impact of RPA technologies on accounting systems," Muhasebe ve Finansman Dergisi, vol. 82, 2019, pp. 235-250. DOI: https://doi.org/10.25095/mufad.536083.

[13] C. Cewe, D. Koch and R. Mertens, "Minimal effort requirements engineering for robotic process automation with test driven development and screen recording," In: Teniente E., Weidlich M. (eds) Business Process Management Workshops. BPM 2017. Lecture Notes in Business Information Processing, vol 308. Springer, Cham, 2018. https://doi.org/10.1007/978-3-319-74030-0_51.

[14] A. Leshob, M. Bédard and H. Mili, "Robotic process automation and business rules: a perfect match," Proceedings of the 17th International Joint Conference on e-Business and Telecommunications (ICETE 2020), vol. 3, 2020, pp. 119-126.

[15] M. Schmitz, C. Dietze and C. Czarnecki, "Enabling Digital Transformation Through Robotic Process Automation at Deutsche Telekom," In: Urbach N., Röglinger M. (eds) Digitalization Cases. Management for Professionals. Springer, Cham, 2019. https://doi.org/10.1007/978-3-319-95273-4_2.

[16] S. Anagnoste, "Robotic process automation in pharma: three case studies," In Proceeding of BASIQ 2018 Conference: New Trends in Sustainable Business and Consumption, 31 May - 3 June 2018, Heidelberg, Germany, pp. 779-784. 
[17] K. Osmundsen, J. Iden and B. Bygstad, "Organizing robotic process automation: balancing loose and tight coupling," In Proceedings of the 52nd Hawaii international conference on system sciences, 2019, pp. 6918-6926. DOI: 10.24251/HICSS.2019.829.

[18] S. Aguirre and A. Rodriguez, "Automation of a Business Process Using Robotic Process Automation (RPA): A Case Study,” In: Figueroa-García J., López-Santana E., Villa-Ramírez J., Ferro-Escobar R. (eds) Applied Computer Sciences in Engineering. WEA 2017. Communications in Computer and Information Science, vol 742. Springer, Cham, 2017. https://doi.org/10.1007/978-3-319-66963-2_7.

[19] D. Fernandez and A. Aman, "Impacts of robotic process automation on global accounting services," Asian Journal of Accounting and Governance, 2018, vol. 9, pp. 123-132.

[20] M. Ratia, J. Myllärniemi and N. Helander, "Robotic process automation-creating value by digitalizing work in the private healthcare?," Proceedings of the 22nd International Academic Mindtrek Conference, 2018, pp. 222-227.

[21] N. Zhang and B. Liu, "The key factors affecting RPA-business alignment," Proceedings of the 3rd International Conference on Crowd Science and Engineering, 2018, pp. 1-6.

[22] D. Barbuzzi, A. Massaro, A. Galiano, L. Pellicani, G. Pirlo, and M. Saggese "Multi-domain intelligent system for document image retrieval," Int. J. Adaptive and Innovative Systems, vol. 2, no. 4, 2020, pp. 282-297, https://doi.org/10.1504/IJAIS.2019.108381

[23] D. Barbuzzi, A. Massaro, V. Vitti, A. Galiano, B. Boussahel, C. Veronica, N. Malfettone, M. Saggese, F. Forieri, "Intelligent System for Image Retrieval (ISIR) based on CBIR technology: Industrialization process," Journal of Next Generation Information Technology (JNIT), vol. 8, no. 2, 2017, pp. 1-13.

[24] A. Massaro, P. Lisco, A. Lombardi, A. Galiano and N. Savino "A case study of research improvements in an service industry upgrading the knowledge base of the information system and the process management: data flow automation, association rules and data mining," International Journal of Artificial Intelligence and Applications (IJAIA), vol. 10, no. 1, pp. 25-46, 2019. http://dx.doi.org/10.5121/ijaia.2019.10103

[25] A. Massaro, V. Vitti, P. Lisco, A. Galiano, and N. Savino, "A business intelligence platform implemented in a big data system embedding data mining: a case of study," International Journal of Data Mining \& Knowledge Management Process (IJDKP), vol. 9, no.1, 2019, pp. 1-20. https://doi.org/10.5121/IJDKP.2019.9101

[26] A. Massaro, A. Leogrande, P. Lisco, A. Galiano, and N. Savino, "Innovative BI approaches and methodologies implementing a multilevel analytics platform based on data mining and analytical models: a case of study in roadside assistance services," International Journal on Soft Computing, Artificial Intelligence and Applications (IJSCAI), vol.8, no.1, 2019, pp. 17-36. http://dx.doi.org/10.5121/ijscai.2019.8102

[27] A. Massaro, A. Panarese, M. Gargaro, C. Vitale, and A. M. Galiano "Implementation of a decision support system and business Intelligence algorithms for the automated management of insurance agents activities," International Journal of Artificial Intelligence \& Applications (IJAIA), vol. 12, no. 3, 2021. http://dx.doi.org/10.5121/ijaia.2021.12301

[28] A. Massaro, A. Panarese, M. Gargaro, A. Colonna, and A. Galiano "A case study of innovation in the implementation of a DSS system for intelligent insurance hub services," Computer Science and Information Technology, vol. 9, no. 1, 2021, pp. 14 - 23. http://dx.doi.org/10.13189/csit.2021.090102

[29] A. Massaro, and A. Galiano, "Re-engineering process in a food factory: an overview of technologies and approaches for the design of pasta production processes," Production \& Manufacturing Research, Vol. 8, No. 1, 2020, pp. 80-100, https://doi.org/10.1080/21693277.2020.1749180

[30] A. Massaro, A. Galiano, A. Mustich, D. Convertini, V. Maritati, A. Colonna, N. Savino, A. Pace, and L. Iaquinta, "A case study of process engineering of operations in working sites through data mining and augmented reality," International Journal of Data Mining \& Knowledge Management Process (IJDKP), vol.9, no.5, 2019, pp. 1-20. https://doi.org/10.5121/ijdkp.2019.9501

[31] A. Galiano, A. Massaro, D. Barbuzzi, L. Pellicani, G. Birardi, B. Boussahel, F. De Carlo, V. Calati, G. Lofano, L. Maffei, M. Solazzo, V. Custodero, G. Frulli, E. Frulli, F. Mancini, L. D’Alessandro, and F. Crudele, "Machine to machine (M2M) open data system for business intelligence in products massive distribution oriented on big data," International Journal of Computer Science and Information Technologies (IJCSIT), vol. 7, no. 3, 2016, pp. 1332-1336. http://www.ingeltech.com/wordpress/wp-content/uploads/2016/05/ijcsit2016070363.pdf

[32] A. Massaro, V. Maritati, and A. Galiano, "Data mining model performance of sales predictive algorithms based on RapiMiner workflow," International Journal of Computer Science \& 
International Journal of Data Mining \& Knowledge Management Process (IJDKP)

Vol.12, No.1, January 2022

Information Technology (IJCSIT), vol. 10, no. 3, 2018, pp. 39-56. DOI: 10.5121/ijcsit.2018.1030. https://doi.org/10.5121/IJCSIT.2018.10303

[33] A. Massaro, V. Maritati, N. Savino, A. Galiano, D. Convertini, E. De Fonte, M. Di Muro, "A study of a health resources management platform integrating neural networks and DSS telemedicine for homecare assistance," Information, vol. 9, no. 176, 2018, pp. 1-20. https://doi.org/10.3390/info9070176

[34] A. Massaro, "Electronic in advanced research industry: from industry 4.0 to industry 5.0 advances," Wiley/IEEE, ISBN: 9781119716877. https://books.google.it/books?id=LP5FEAAAQBAJ

[35] A. Massaro, V. Maritati, N. Savino and A. Galiano, "Neural Networks for Automated Smart Health Platforms oriented on Heart Predictive Diagnostic Big Data Systems," 2018 AEIT International Annual Conference, 2018, pp. 1-5. https://doi.org/10.23919/AEIT.2018.8577362 .

[36] A. Massaro, "Information Technology Infrastructures Supporting Industry 5.0 Facilities," in Electronics in Advanced Research Industries: Industry 4.0 to Industry 5.0 Advances, IEEE, 2022, pp.51-101, https://doi.org/10.1002/9781119716907.ch2 .

[37] A. Massaro, D. Barbuzzi, V. Vitti, A. Galiano, M. Aruci, and G. Pirlo "Predictive sales analysis according to the effect of weather," Published in RTA-CSIT 2016. https://citeseerx.ist.psu.edu/viewdoc/download?doi=10.1.1.1081.528\&rep=rep1\&type=pdf

\section{AUTHORS}

Nicola Magaletti, Business development manager with a degree in mechanical engineering with over 30 years of work experience in structured companies, for which he works in the management of innovation processes and in the launch of new business initiatives in the industrial consultancy sector. Since 2018 he has been part of the Lum Enterprise team as Operational Manager and Technical-Scientific Manager of the "Smart District 4.0" R\&D project of which the company is the lead.

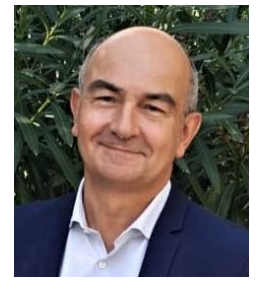

Gabriele Cosoli. Senior IT Specialist and Solution architect with a degree in Computer Science and over five years of previous experience, specialized in the analysis and design of ICT solutions in various application areas and technological frameworks. Certified on "Machine Learning by Stanford University on Coursera" Master on "Agile and Digital Project Management - Adavanced Course" at 24ORE Business School.

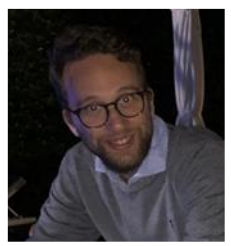

Angelo Leogrande. Senior IT Specialist and Solution architect with a degree in Computer Science and over five years of previous experience, specialized in the analysis and design of ICT solutions in various application areas and technological frameworks. Certified on "Machine Learning by Stanford University on Coursera" Master on "Agile and Digital Project Management - Adavanced Course" at 24ORE Business School.

Alessandro Massaro. Professor Alessandro Massaro (ING/INF/01, FIS/01, FIS/03) carried out scientific research at the Polytechnic University of Marche, at CNR, and at Italian Institute of Technology (IIT) as Team Leader by activating laboratories for nanocomposite sensors for industrial robotics. He is in MIUR register as scientific expert in competitive Industrial Research and social development. He was the head of the Research and Development section and scientific director of MIUR Research Institute Dyrecta Lab Srl. Member of the International Scientific Committee of

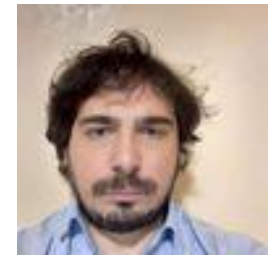
Measurers IMEKO and IEEE Senior member, he received an award from the National Council of Engineers as Best Engineer of Italy 2018 (Top Young Engineer 2018). He is currently researcher at LUM Enterprise srl, and professor at LUM University Libera Università Mediterranea "Giuseppe Degennaro". 